\title{
Exploring the Practice of "Integration of Production and Education" Collaborative Education Mode in the Local Universities Under the Background of New Engineering: Take Yancheng Teachers University as an Example
}

\author{
Yan-Qing Wang* \\ School of Chemistry and Environmental Engineering, Yancheng Teachers University \\ No. 2, Hope Avenue South Road, Jiangsu 224007, China \\ E-mail: wjloxxj@163.com \\ Zheng-Hao Fei \\ School of Chemistry and Environmental Engineering, Yancheng Teachers University \\ No. 2, Hope Avenue South Road, Jiangsu 224007, China \\ E-mail: feizhenghao@163.com
}

The research is supported by Jiangsu Higher Education Teaching Reform Research Project (2019JSJG176)

\section{Abstract}

Guided by the New Engineering concept, the applied chemistry major of Yancheng Teachers University, which aims at the characteristics of local economic development in Jiangsu Province, especially Yancheng, constructed a modular curriculum system, a multi-dimensional practice platform and a double-qualified teacher team, a process assessment and incentive mechanism, a "multi-dimensional coordination" quality evaluation system to form the "integration of industry and education" education path and significantly improved the students' entrepreneurial innovation and engineering practice ability.

Keywords: new engineering; cooperative education mode; integration of production and education; entrepreneurship and innovation; engineering practice ability

DOI: $10.7176 / \mathrm{JEP} / 12-18-06$

Publication date:June $30^{\text {th }} 2021$

\section{Introduction}

In the so-called new engineering, "engineering" refers to the engineering discipline and "new" is the orientation which means being "newly-developing, late-model and neonatal". At present, a new round of scientific revolution and industrial transformation is accelerating in the world, which causes the change of social requirements on the quality and structure of talents, and thus causes the reform of engineering education talent training programs and concepts ${ }^{[1-3]}$.

"Integration of production and education" is a necessary condition for colleges and universities to cultivate applied talents, which is determined by the practical attribute of colleges and universities' education work and the intrinsic law of students' learning and becoming talents ${ }^{[4-6]}$. Based on the new engineering concept, the "community" and vines loch hawking's theory of "cooperative learning", and "collaborative education ideas", the applied chemistry major of Yancheng Teachers University achieved the transform of group training objectives, curriculum, teaching methods and evaluation system to establish the resource sharing, complementary advantages and common development of fusion education cooperative education mechanism to improve the quality of talent cultivation and the development of local economy and society.

2. The establishment of the talent training scheme of the "integration of industry and education" mechanism and the corresponding curriculum system under the new engineering concept.

2.1 Construction of "integration of production and education" of a talent training program based on the principle of "Three Entries".

The brand specialty of applied chemistry affiliated to Yancheng Teachers University, which takes moral education as the foundation, ability cultivation as the orientation, "Three Entries" as the principle, and reverse design as the method, built a talent training program of "integration of production and education" comprehensively to make students character, knowledge and competency framework into the "Frame"; to make standards and requirements that refer to the national standard for the teaching quality of chemistry specialty, the international certification standard for chemical engineering education, and the concept of excellence, collaboration, internationalization and informatization into the "Plate"; to make course into the "Root", and constructed the three-dimensional "two-subject" education mode of "declarative knowledges-procedural knowledges-strategic knowledges-motor skills-attitudes, emotions and values". 


\subsection{Construction of corresponding curriculum system.}

According to the requirements of chemical enterprises or industries, the applied chemistry major of Yancheng Teachers University conducted position positioning and position analysis and optimized five progressive course modules of "general courses, professional courses, cross-personality development, innovation and entrepreneurship, and concentrated practice" to build a "layered and modular" course system.

\section{Exploration of the practical teaching path of "integration of production and education" under the new engineering concept.}

Guided by the concept of "honest", the applied chemistry major of Yancheng Teachers University established a progressive practical teaching system, diversified practical teaching modes, and multi-dimensional practical teaching platform, and formulated an applied talent training mode and path of "integration production and education" to comprehensively improve the quality of applied and innovative talents.

The applied chemistry major of Yancheng Teachers University successfully applied for the first-phase project of Jiangsu University Brand Major Construction Project (with the funding of 9.6 million yuan from the Provincial Department of Education), "Chemical Engineering and Technology Comprehensive Training Center" provincial experimental platform project in Jiangsu Province in 2013 (with the funding of 2 million yuan from the Provincial Department of Education), the construction project of "Chemical Engineering and Technology Experimental Teaching Platform" funded by the central financial development fund in 2014, the 2013 Jiangsu Provincial Local Education Supplementary Project-Chemical Engineering Practice Education Platform of Yancheng Teachers University, etc. These accumulative investment of nearly 15 million yuan has greatly improved the teaching infrastructure.

The applied chemistry major of Yancheng Teachers University established close school-enterprise cooperation and industry-university-research cooperation relationship with relevant enterprises or industries, mainly focusing on the local characteristic industries such as new energy automobile industry, chemical industry, environmental protection industry, etc. For example, a regional education alliance with Yancheng Binhai Chemical Industrial Park and local chemical enterprises has been established, and cooperative relations with Yancheng Jinming Pharmaceutical Co., Ltd., Yancheng Ruier New Technology Co., Ltd., Jiangsu Lvfangyuan Biological Technology Co., Ltd., and Jiangsu Guochuang Environmental Protection Technology Co., Ltd., etc has been begun. On the existing basis, applied chemistry major will further explore the "integration of production and education" education practice path to improve the quality of student training.

\section{Build a high standard of teaching staff by means of "internal training and external introduction".}

Applied chemistry major of Yancheng Teachers University by means of "internal training and external introduction" carried out the doctoral, international, team-based and double-qualified training to increase the proportion of application-oriented personnel training, and promote the overall improvement of teachers' teaching and service to local industries through encouraging institutions of higher learning and enterprises to carry out personnel training and collaborative innovation in response to the major needs of industrial technology.

In addition, the applied chemistry major of Yancheng Teachers University and enterprises jointly build a team of full-time and part-time teachers. At the beginning, part-time teachers from the front line of enterprises are selected as practical skills courses, so as to form a reasonably structured "double-qualified" teaching team composed of full-time teachers of this major and technical experts (part-time teachers) from enterprises. Secondly, the critical point is to improve their practical ability for the full-time teachers who lack practical experience but have higher theoretical knowledge and academic qualifications. Adhering to the guiding ideology of "taking vocational ability as the standard, studying alternatively as the means, and the enterprises' participation and guidance", the applied chemistry major reached a zero-distance cooperation mode with enterprises, so as to create a large number of opportunities for full-time teachers to participate in enterprises' technical transformation projects and improve their practical ability. What's more, the level of part-time teachers should be improved. The training of part-time teachers is mainly to improve their educational and teaching ability, encourage them to continue their studies, and strengthen their theoretical basis. Last but not least, teachers should be encouraged to help and learn from each other to improve the teaching level of part-time teachers.

\section{Research on the guarantee mechanism of the education system of "integration of production and education".}

The applied chemistry major followed "Need-Motivation-Behavior" incentive paths and built "starting from the actual demand of power-driven mechanism", "achievement sharing risk-sharing mechanism of joint training" and "responsibilities clear pragmatic multiple interactive mechanism". Suggestions are put forward to guarantee the education mechanism of "integration of production and education" to improve the system of modern school and actively promote the omni-directional integration of resources, personnel, technology, management and culture. 
Centered on the key links of productive training, technology research and development, and inspection and testing, the joint ventures and cooperation between schools and enterprises in accordance with the law have been promoted to set up physical institutions, so as to realize market-oriented and specialized operations. Further improving the level of collaborative education contributes to cultivate high-quality applied talents for the society and local industries.

6. Multi-interaction mechanism of clearing powers and responsibilities and driving for results.

6.1 Establish a feedback and consultation mechanism between the applied Chemistry major, industry, enterprises and scientific research institutes.

Based on the talent demand and quality information feedback from industries, enterprises and scientific research institutes, the talent training program should be adjusted to promote the construction of applied chemistry major, so as to meet the needs of the combination of production, education and research and cultivate high-quality talents to meet the needs of social and regional development.

6.2 Establish a mechanism for the government and enterprises to deeply participate in talent training. Industry, enterprises and scientific research institutes should be participated in the research and formulation of training objectives, teaching plans, teaching contents and training methods to deeply participate in the training process and improve the quality of talent training.

6.3 Establish the exchange mechanism between the applied chemistry major and government, industry, enterprises and research institutes.

Through the government, industry, enterprises and scientific research institutes, the teacher and student incentive funds, innovative research and development projects should be set up to promote the exchange between schools, enterprises and research institutes and improve the quality of applied talents training.

\section{References}

[1] Sun Hongxia, Li Feng, Cao Yanan, Ding Lining (2021). Exploration on the Training Mode of Computer Professionals Based on the Concept of "New Engineering". Journal of Education and Practice, 12(08): 2124.

[2] Zhang Daliang (2017). Change according to the time, start new construction and develop new engineering. China University teaching, 4: 4-9.

[3] Yan-Li Bai, Jian Lu, Heng Li, Jin Xu (2019). Design and Implementation of Professional Training Project of Cooperative Industrial Robot under Background of "Dual Creative " and "New Engineering". Education Teaching Forum, 15: 40-41.

[4] Meng lijiu, Zhao Qi (2019). Concept orientation of new engineering construction and action choice of local engineering colleges. Research on maritime education, 36 (02): 44-49.

[5] Xiang-Bin Meng, Qian Zhang, Wei-Hua Tian, Jian-Ying Hu (2019). Research on the Training Mode of Innovative and Entrepreneurial Talents in Applied Engineering Colleges under the Background of New Engineering. Journal of Shenyang Institute of Engineering, 15: 116-119.

[6] Zhong Denghua (2017). Connotation and action of new engineering construction. Research on higher engineering education, 3: 1-6. 